\title{
Avaliação do contexto de trabalho e burnout em residentes e preceptores
}

\author{
Work context assessment and burnout in residents and preceptors \\ Evaluación del contexto laboral y Agotamiento Psicológico en residentes y preceptores \\ Nayana Adour Vasconcelos ${ }^{1 *}$, Cláudio Antônio da Costa Neto², Marília Agostinho de Lima Gomes ${ }^{3}$, \\ Luciana Moser de Sena Otelo ${ }^{4}$, Mateus Estevam Medeiros-Costa 5 .
}

\begin{abstract}
RESUMO
Objetivo: avaliar o contexto de trabalho e Síndrome de Burnout em residentes e preceptores dos programas de residência médica em ortopedia e traumatologia do Estado pernambucano. Métodos: Trata-se de um estudo exploratório e descritivo, de cunho quantitativo. Para tanto, foram aplicados dois instrumentos, a Escala de Avaliação do Contexto de Trabalho (EACT) e Escala de Caracterização de Burnout (ECB). Resultados: dos fatores que constituem o contexto de trabalho, a organização do trabalho é a dimensão mais crítica, já a Síndrome de Burnout apresentou índices baixos-moderados para exaustão emocional, desumanização e decepção no trabalho, mas os sintomas de esgotamento foram mais acentuados. As condições de trabalho vivenciadas entre residentes e preceptores são diferentes. Conclusão: o contexto de trabalho da residência médica corrobora o surgimento da síndrome de Burnout. A implantação de políticas e programas voltados à promoção da saúde, qualidade de vida e bem-estar dos preceptores e residentes é de extrema importância. Investigações de natureza longitudinais, que visem explorar a relação e impacto do contexto de trabalho da residência médica e a manifestação do Burnout são necessárias.
\end{abstract}

Palavras-chave: Internato e residência, Esgotamento psicológico, Condições de trabalho.

\begin{abstract}
Objective: to evaluate the work context and Burnout syndrome in residents and preceptors of the Pernambuco State Orthopedics and Traumatology residency programs. Methods: This is an exploratory and descriptive study of quantitative nature. Therefore, two instruments were applied, Escala de Avaliação do Contexto de Trabalho (EACT) and Escala de Caracterização de Burnout (ECB). Results: of the factors that make up the work context, work organization is the most critical dimension, since the Burnout syndrome presented lowmoderate rates for emotional exhaustion, dehumanization and disappointment at work, but the symptoms of exhaustion were more pronounced. The working conditions experienced between residents and tutors are different. Conclusion: The working context of the medical residency corroborates the emergence of burnout syndrome. The implementation of policies and programs aimed at promoting the health, quality of life and wellbeing of preceptors and residents is of utmost importance. Longitudinal investigations aimed at exploring the relationship and impact of the working context of the medical residency and the manifestation of burnout are necessary.
\end{abstract}

Keywords: Internship and residency, Psychological burnout, Working conditions.

\footnotetext{
${ }^{1}$ Pontifícia Universidade Católica de Campinas (PUC-Campinas), Campinas - SP.

*E-mail: nayana.adour@gmail.com

2 Universidade Federal de São Paulo (Unifesp), São Paulo - SP.

${ }^{3}$ Instituto de Medicina Integrada Professor Fernando Figueira (IMIP), Recife - PE.

${ }^{4}$ Hospital Miguel Arraes (HMA), Recife - PE.

${ }^{5}$ Universidade Federal do Rio Grande do Norte (UFRN), Natal - RN.
} 
RESUMEN

Objetivo: evaluar el contexto laboral y el síndrome de Burnout en residentes y preceptores de los programas de residencia de Pernambuco State Orthopedics and Traumatology. Métodos: Este es un estudio exploratorio y descriptivo de naturaleza cuantitativa. Con este fin, se aplicaron dos instrumentos, Escala de Avaliação do Contexto de Trabalho (EACT) y la Escala de Caracterização de Burnout (ECB). Resultados: De los factores que conforman el contexto laboral, la organización del trabajo es la dimensión más crítica, ya que el síndrome de Burnout presentó tasas bajas y moderadas de agotamiento emocional, deshumanización y decepción en el trabajo, pero los síntomas de agotamiento fueron más pronunciados. Las condiciones de trabajo experimentadas entre residentes y tutores son diferentes. Conclusión: El contexto laboral de la residencia médica corrobora la aparición del síndrome de Burnout. La implementación de políticas y programas destinados a promover la salud, la calidad de vida y el bienestar de los preceptores y residentes es de suma importancia. Son necesarias investigaciones longitudinales destinadas a explorar la relación y el impacto del contexto laboral de la residencia médica y la manifestación del agotamiento.

Palabras clave: Internado y residencia, Agotamiento psicológico, Condiciones de trabajo.

\section{INTRODUÇÃO}

O processo de trabalho médico é conhecido por seus elevados padrões de exigência e diante disso, o período de formação profissional inclui a residência médica. A residência, por sua vez, é uma especialização que visa proporcionar o ensino em serviço, com carga horária de 60h semanais e duração mínima de dois anos, em caráter de dedicação exclusiva. Esse período é marcado pelo desgaste físico e emocional, já que o jovem médico exerce a dupla função de estudante-trabalhador e isso pode acarretar ao adoecimento (CAVALCANTI IL, et al., 2018).

Por sua vez, a preceptoria é pautada na intersecção entre ensino e serviço, em que a atividade desenvolvida na preceptoria, torna, tanto profissional de saúde quanto educador (AUTONOMO FRDO, et al 2015). Na maioria das vezes, o preceptor desenvolve suas tarefas em locais inadequados às atividades de ensino, não se percebendo capacitado e estimulado, o que dificulta a formação dos residentes. Sabido também que o treinamento e capacitação de médicos e demais trabalhadores à preceptoria se dar durante 0 período de trabalho, sendo um entrave devido à demanda e sobrecarga de trabalho (SANT'ANA ERRD e PEREIRA ERS, 2016).

Estudos mais recentes reiteram que o profissional médico encontra-se, submetido a este tipo de relação negativa por conta das elevadas cargas de trabalho, turnos extensos, além das jornadas noturnas, relações interpessoais entre colegas e pacientes, frustrações terapêuticas e, em muitos casos, ausência de materiais para realização do trabalho bem feito.

Entre a categoria, aqueles que cursam a residência médica são mais vulneráveis, já que necessita de constante treinamento e intensa inserção na rotina da especialidade desejada, além de funções burocráticas, responsabilidades frente aos pacientes, tomadas de decisão, planejamento da carreira e pessoal (PASTURA PSVC, et al. 2019).

O estabelecimento do nexo causal aparentemente é menos complicado quando as queixas estão voltadas a deterioração física. Porém quando se refere ao nexo entre o adoecimento mental e o contexto de trabalho, essa tarefa parece ser árdua. Isso ocorre com alguns profissionais que desenvolvem distúrbios psíquicos relacionados ao trabalho, mas que não tem o nexo reconhecido frente à dificuldade da associação entre adoecimento mental e trabalho (PORTZ RM e AMAZARRAY MR, 2019).

Tais aspectos colocam em voga a necessidade de investigações que tomem como cenário o contexto de trabalho da residência médica. Alguns estudos são encontrados acerca de problemas de saúde entre acadêmicos de medicina. Mas, são escassos estudos que viabilizem a relação e impacto do contexto de trabalho da residência médica na manifestação do Esgotamento Psicológico ou, como é mais conhecida, a Síndrome de Burnout (MEDEIROS MRB, et al. 2018). 
A noção de contexto de trabalho é apoiada no conceito encontrado em Ferreira MC e Mendes AM (2003) como Contexto de Produções de Bens e Serviços, sendo a relação material, organizacional e social, retratada na atividade de trabalho e nas estratégias de mediação tanto individuais quanto coletivas, as quais se fazem necessárias para a concretização do trabalho. Para tanto, esse construto se divide em três fatores: Organização do Trabalho, Condições de Trabalho e Relações Socioprofissionais.

De acordo com Silva JF et al. (2020) a terminologia Burnout foi empregada em 1974 por Freuden Berger, um psicanalista que estava experienciando sentimento de fracasso no trabalho, exaustão acarretada por excessivo desgaste de energia, sintomas depressivos, irritabilidade, aborrecimento, dentre outros sintomas, ou seja, uma psicopatologia que tinha como causa o esgotamento profissional.

Tal termo resulta do verbo inglês to burn out, que toma como significado, em língua portuguesa, "queimar por completo", "desgastar-se" ou "esgotar-se". A Síndrome Burnout tem ganhado espaço em meio às comunicações científicas. Tal risco psicossocial é multifacetado e a definição mais usada para descrever tal fenômeno é a de Maslach C (2005), em que a síndrome é constituída por três dimensões: exaustão emocional, despersonalização e reduzida realização pessoal.

Desse modo, por se tratar de um tema atual, que ainda está ganhando notoriedade entre as comunicações científicas, daí a importância de se averiguar tais fenômenos a fim de auxiliar os profissionais a identificarem os sinais e seguirem as diretrizes de prevenção e tratamento com a finalidade de tornar cada vez mais baixas as estatísticas de trabalhadores que sofrem com o Esgotamento Psicológico (SILVA JF et al., 2020). Ademais, foram constatadas que a deterioração das condições de trabalho, relações socioprofissionais e organização do trabalho, repercutem na manifestação dos sintomas da síndrome entre as equipes de saúde (LACERDA RB, et al, 2016).

Percebe-se, assim, a importância de averiguar a natureza da relação entre o contexto de trabalho e a saúde mental dos trabalhadores da residência médica. Esta pesquisa visa preencher essa lacuna e, visa analisar a repercussão do contexto de trabalho e Síndrome Burnout entre residentes e preceptores das residências de ortopedia e traumatologia do estado pernambucano.

\section{MÉTODOS}

Para traçar o perfil da população estudada foram aplicados questionários para verificar o perfil sociodemográfico, o contexto de trabalho e Burnout entre os residentes e preceptores da residência. Esses trabalhadores foram abordados no seu período de trabalho e só responderam os questionários após concordar com a participação do estudo. Os instrumentos aplicados contêm questões sobre o perfil sociodemográfico dos participantes, o segundo é a Escala de Avaliação do Contexto de Trabalho (EACT) e o terceiro é a Escala de Caracterização de Burnout (ECB).

Em dados técnicos a EACT se divide em três fatores: Organização do Trabalho (11 itens, confiabilidade de 0,72), Condições de Trabalho (10 itens, com confiabilidade de 0,89) e Relações Sociais de Trabalho (10 itens, com confiabilidade de 0,87 ), empregando o tipo Likert de cinco pontos (FERREIRA MC e MENDES AM, 2003). A ECB averigua a incidência do Burnout, por meio de 35 itens distribuídos em três dimensões (exaustão emocional, despersonalização e reduzida realização profissional). O ECB é respondido em uma escala tipo Likert de cinco pontos variando de "Nunca" (1) a "Sempre" (5) (TAMAYO MR e TRÓCCOLI BT, 2009).

Os profissionais de medicina foram abordados presencial e virtualmente, após concordar e assinar o Termo de Consentimento Livre e Esclarecido (TCLE) para responder os instrumentos (EACT e ECB e questionário sociodemográfico). O presente estudo cumpriu com as orientações éticas e foi aprovado pelo Comitê de Ética Instituto de Medicina Integral Prof. Fernando Figueira (CAAE: 20185419.2.0000.5201).

Com o auxílio do programa Statistical Package for the Social Sciences (SPSS, v. 22.0) foram executadas as análises estatísticas descritivas, como média e desvio-padrão. Para comparação das médias foi utilizado o teste t para amostras independentes e a ANOVA unidirecional. Regressões múltiplas foram realizadas para verificação da influência do contexto de trabalho sob a manifestação da Síndrome de Burnout. A consistência interna das duas escalas foi testada por intermédio do alfa de Cronbach (a). 


\section{RESULTADOS}

A amostra do presente estudo foi composta por 76 médicos, sendo 46 residentes e 30 preceptores. Em sua maioria são homens ( $81,6 \%)$, com idade média de $31,71 \pm 6,01$ anos, variando em 25 e 55 anos, casados ou que vivem em união consensual estável (55,3\%), sem filhos (64,5\%). Em sua grande maioria, os médicos trabalham mais de 48 horas semanais $(92,1 \%)$, os quais iniciaram suas atividades há três anos $(50,7 \%)$.

A consistência interna dos fatores da EACT foi conferida e apresentou alfa de Cronbach de 0,96 para o fator Relações Socioprofissionais e de 0,92 para Condições de Trabalho, já o fator Organização do Trabalho manteve alfa de Cronbach de 0,85 (Tabela 1). Conforme Streiner D (2003) o alfa deve apresentar coeficientes com índices superiores a 0,80.

Quanto ao contexto de trabalho da residência de ortopedia e traumatologia, as relações socioprofissionais foi crítica, já que apresentou escores médios de $2,85 \pm 0,84$. Dentre as variáveis que constituem tal fator, existem disputas profissionais no local de trabalho $(3,31 \pm 1,36)$, A distribuição das tarefas é injusta $(3,32 \pm 1,31)$, os funcionários são excluídos das decisões $(3,03 \pm 1,22)$ e A distribuição de tarefas é injusta $(3,03 \pm 1,21)$, foram as mais críticas (Tabela $\mathbf{1}$ ).

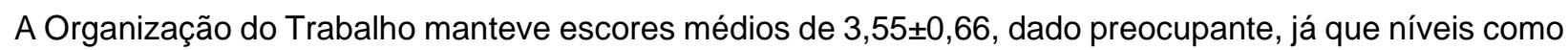
esse indica "situação-limite", vulnerável ao mal-estar e risco de adoecimento. Ademais, as situações: Existe forte cobrança por resultados $(4,03 \pm 0,99)$; O ritmo do trabalho é excessivo $(3,99 \pm 0,84)$; as normas para execução das tarefas são rígidas $(3,86 \pm 0,99)$; e, Falta tempo para realizar pausas de descanso no trabalho $(3,86 \pm 1,03)$, precisam ser atenuadas ou eliminadas, pois representam forte risco de adoecimento (Tabela 1).

As Condições de Trabalho mantiveram escores moderados $(2,62 \pm 1,05)$, o que demonstra não haver tantos problemas relacionados à qualidade do ambiente físico, posto de trabalho, equipamentos e material disponibilizados para a execução das tarefas.

No entanto, dentre as variáveis dessa dimensão, O mobiliário existente no local de trabalho é inadequado e O ambiente físico é desconfortável, foram os mais representativos, com escores médios de 2,86 $\pm 1,29$ e 2,74 $\pm 1,32$, respectivamente (Tabela 1 ). 
Tabela 1 - Avaliação do contexto de trabalhos dos residentes e preceptores de ortopedia e traumatologia, $\mathrm{n}=76$. Recife-PE, 2019.

\begin{tabular}{|c|c|c|}
\hline Variáveis & Média & $\begin{array}{l}\text { Desvio } \\
\text { Padrão }\end{array}$ \\
\hline As tarefas não são claramente definidas & 2,71 & 1,043 \\
\hline A autonomia e inexistente & 2,74 & 1,025 \\
\hline A distribuição das tarefas é injusta & 3,03 & 1,211 \\
\hline Os funcionários são excluídos das decisões & 3,03 & 1,222 \\
\hline Existem dificuldades na comunicação entre chefia e subordinados & 2,82 & 1,373 \\
\hline Existem disputas profissionais no local de trabalho & 3,32 & 1,319 \\
\hline Falta integração no ambiente de trabalho & 2,91 & 1,157 \\
\hline A comunicação entre funcionários é insatisfatória & 2,82 & ,989 \\
\hline Falta apoio das chefias para o meu desenvolvimento profissional & 2,84 & 1,255 \\
\hline $\begin{array}{l}\text { As informações que preciso para executar minhas tarefas são de } \\
\text { difícil acesso }\end{array}$ & 2,28 & ,974 \\
\hline Relações Socioprofissionais $(\alpha: 0,96)$ & 2,85 & 843 \\
\hline O ritmo do trabalho é excessivo & 3,99 & 841 \\
\hline As tarefas são cumpridas com pressão de prazos & 3,75 & ,968 \\
\hline Existe forte cobrança por resultados & 4,03 & ,993 \\
\hline As normas para execução das tarefas são rígidas & 3,86 & ,989 \\
\hline Existe fiscalização do desempenho & 3,72 & 1,066 \\
\hline O número de pessoas é insuficiente para se realizar as tarefas & 3,54 & 1,331 \\
\hline Os resultados esperados estão fora da realidade & 2,67 & 1,038 \\
\hline Existe divisão entre quem planeja e quem executa & 3,09 & 1,180 \\
\hline As tarefas são repetitivas & 3,47 & ,871 \\
\hline Falta tempo para realizar pausas de descanso no trabalho & 3,86 & 1,029 \\
\hline As tarefas executadas sofrem descontinuidade & 2,99 & ,973 \\
\hline Organização do Trabalho $(\alpha: 0,85)$ & 3,55 & 657 \\
\hline As condições de trabalho são precárias & 2,45 & 1,193 \\
\hline O ambiente físico é desconfortável & 2,74 & 1,320 \\
\hline Existe muito barulho no ambiente de trabalho & 2,51 & 1,183 \\
\hline O mobiliário existente no local de trabalho é inadequado & 2,86 & 1,293 \\
\hline $\begin{array}{l}\text { Os instrumentos de trabalho são insuficientes para realizar as } \\
\text { tarefas }\end{array}$ & 2,67 & 1,237 \\
\hline $\begin{array}{l}\text { O posto/estação de trabalho é inadequado para a realização das } \\
\text { tarefas }\end{array}$ & 2,53 & 1,172 \\
\hline $\begin{array}{l}\text { Os equipamentos necessários para realização das tarefas são } \\
\text { precários }\end{array}$ & 2,64 & 1,303 \\
\hline O espaço físico para realizar o trabalho é inadequado & 2,49 & 1,160 \\
\hline $\begin{array}{l}\text { As condições de trabalho oferecem riscos à segurança das } \\
\text { pessoas }\end{array}$ & 2,63 & 1,209 \\
\hline O material de consumo é insuficiente & 2,59 & 1,202 \\
\hline Condições de Trabalho ( $\alpha: 0,92)$ & 2,62 & 1,05 \\
\hline
\end{tabular}

Fonte: Vasconcelos NA, et al. 2019. 
De acordo com os dados elucidados na Tabela 2, se verifica que os fatores Exaustão Emocional e Desumanização possuem uma boa consistência interna, com 0,85 , cada. O fator Decepção no Trabalho conferiu um alfa de 0,84 . Diante desse dado se constata a consistência interna e adequabilidade da ECB para fins de análise. A Síndrome de Burnout apresentou níveis baixo-moderados nas três dimensões, sendo que a exaustão emocional foi a mais recorrente, com 2,63 $\pm 0,68$. Seguido da dimensão Decepção no Trabalho $(2,35 \pm 0,63)$ e Desumanização $(2.23 \pm 0,70)$.

Os residentes e preceptores se mostram satisfeitos, uma vez que, acho que as coisas que realizo no meu trabalho valem a pena, auferiu escores médios de $4,25 \pm 0,82$. Por outro lado, reconhecem também que estão exauridos, já que sinto-me esgotado ao final de um dia de trabalho, Acho que estou trabalhando demais no meu emprego e Sinto que meu trabalho está me destroçando, apresentou altos índices, com 3,82 $\pm 0,90$, $3,49 \pm 1,26$ e $3,76 \pm 1,15$, respectivamente (Tabela 2 ).

Tabela 2 - Avaliação da Síndrome de Burnout entre residentes e preceptores de ortopedia e traumatologia, $\mathrm{n}=76$. Recife-PE, 2019.

\begin{tabular}{|c|c|c|}
\hline Variáveis & Média & $\begin{array}{l}\text { Desvio } \\
\text { Padrão }\end{array}$ \\
\hline Sinto-me esgotado ao final de um dia de trabalho & 3,82 & ,905 \\
\hline Meu trabalho afeta negativamente minha saúde física & 3,16 & 1,189 \\
\hline Sinto que a carga emocional do meu trabalho é superior àquela que posso suportar. & 2,41 & 1,085 \\
\hline Meu trabalho me faz sentir emocionalmente exausto. & 2,97 & 1,265 \\
\hline Acho que estou trabalhando demais no meu emprego. & 3,49 & 1,260 \\
\hline Meu trabalho me exige mais do que posso dar. & 1,80 & ,880 \\
\hline Meu trabalho afeta negativamente meu bem-estar psicológico. & 1,88 & 1,143 \\
\hline Meu trabalho me faz sentir como se estivesse no limite das minhas possibilidades. & 1,66 & 1,078 \\
\hline Sinto que meu trabalho está me destroçando. & 3,76 & 1,153 \\
\hline Eu me sinto sugado pelo meu trabalho. & 2,14 & 1,067 \\
\hline sinto satur & 2,25 & 1,109 \\
\hline Eu me sinto desgastado com meu trabalho. & 2,22 & 1,091 \\
\hline Exaustão Emocional $(\alpha: 0,85)$ & 2,63 & 681 \\
\hline Trato alguns usuários com distanc & 2,4 & 997 \\
\hline Trato alguns usuários c & 2,12 & 1,070 \\
\hline Sinto que alguns usuários são "meus inimigos". & 1,92 & 1,117 \\
\hline Enfureço-me com alguns usuários. & 2,24 & 1,057 \\
\hline Sinto que desagrado a algu & 2,21 & ,838 \\
\hline Perco a & 2,30 & 1,071 \\
\hline Trato alguns usuários & 2,3 & 1,208 \\
\hline & 2, & 1,169 \\
\hline Evito & 2,4 & 1,125 \\
\hline Fico de mau humor quando lido com alguns usuários. & $1, \varsigma$ & ,908 \\
\hline Desumanização $(\alpha: 0,85)$ & 2,23 & ,700 \\
\hline Eu me sinto frust & 2,30 & 1,020 \\
\hline Acho que as c & 4,2 & ,819 \\
\hline Meu trabalho me faz sentir como se estivesse num beco sem saída. & 1,87 & 1,037 \\
\hline Eu me sinto desanimado com meu trabalho. & 2,25 & ,940 \\
\hline Sinto-me desesperado com meu trabalho. & 1,68 & ,867 \\
\hline Acho que meu trabalho parece sem sentido. & 2,01 & 1,000 \\
\hline Eu me sinto inútil & 1,68 & ,927 \\
\hline Eu me sinto identificado com meu trabalho. & 2,71 & 1,294 \\
\hline $\begin{array}{l}\text { Quando me levanto de manhã sinto cansaço só de pensar que tenho que encarar mais } \\
\text { um dia de trabalho. }\end{array}$ & 2,17 & 1,051 \\
\hline Eu me sinto desiludido com meu trabalho. & 2,58 & 1,225 \\
\hline Sinto-me emocionalmente vazio com meu trabalho. & 2,62 & 1,119 \\
\hline & 1,87 & ,914 \\
\hline Eu me sinto cheio de energia para trabalhar. & 2,50 & 1,039 \\
\hline Decepção no Trabalho $(\alpha: 0,84)$ & 2,35 & ,634 \\
\hline
\end{tabular}

Fonte: Vasconcelos NA, et al. 2019. 
Quanto ao sexo dos participantes do estudo, os fatores Condições de Trabalho $(p<0,17)$, Organização do Trabalho $(p<0,66)$, Relação Socioprofissional $(p<0,07)$, Exaustão Emocional $(p<0,07)$, Desumanização $(p<0,54)$ e Decepção no Trabalho $(p<0,06)$ não apresentaram diferenças entre homens e mulheres (Tabela 3). Na Tabela 3, observa-se que a variável Estado Civil não difere entre grupos, mas a variável Atividade Desenvolvida, apresenta diferenças significativas no que diz respeito às condições de trabalho $(p<0,000)$, dos preceptores e residentes. 


\section{Revista Eletrônica Acervo Saúde / Electronic Journal Collection Health | ISSN 2178-2091}

Tabela 3 - Comparação de médias do contexto de trabalho e Síndrome de Burnout entre residentes e preceptores de ortopedia e traumatologia, $\mathrm{n}=76$. Recife-PE, 2019.

\begin{tabular}{|c|c|c|c|c|c|}
\hline Variáveis & Sexo & № & Média & Desvio Padrão & $\mathbf{P}$ \\
\hline \multirow{2}{*}{ Condições Trabalho } & Masculino & 62 & 2,5242 & 1,06397 & \multirow{2}{*}{, 17} \\
\hline & Feminino & 14 & 2,9929 & ,95633 & \\
\hline \multirow{2}{*}{ Organização do Trabalho } & Masculino & 62 & 3,5205 & ,64454 & \multirow{2}{*}{,66 } \\
\hline & Feminino & 14 & 3,6364 & ,72552 & \\
\hline \multirow{2}{*}{ Relação Socioprofissional } & Masculino & 62 & 2,7645 & ,76782 & \multirow{2}{*}{,07 } \\
\hline & Feminino & 14 & 3,2143 & 1,07407 & \\
\hline \multirow{2}{*}{ Exaustão Emocional } & Masculino & 62 & 2,5645 & ,62058 & \multirow{2}{*}{,07 } \\
\hline & Feminino & 14 & 2,9226 & ,86939 & \\
\hline \multirow{2}{*}{ Desumanização } & Masculino & 62 & 2,1839 & 67197 & \multirow{2}{*}{, 54} \\
\hline & Feminino & 14 & 2,4357 & 80728 & \\
\hline \multirow{2}{*}{ Decepção no Trabalho } & Masculino & 62 & 2,2829 & ,60518 & \multirow{2}{*}{,06 } \\
\hline & Feminino & 14 & 2,6264 & ,70942 & \\
\hline \multicolumn{6}{|l|}{ Atividade Desenvolvida } \\
\hline \multirow{2}{*}{ Condições Trabalho } & Residente & 46 & 2,3326 & ,95337 & \multirow{2}{*}{, 00} \\
\hline & Preceptor & 30 & 3,0367 & 1,07559 & \\
\hline \multirow{2}{*}{ Organização do Trabalho } & Residente & 46 & 3,6403 &, 52134 & \multirow{2}{*}{, 17} \\
\hline & Preceptor & 30 & 3,3909 & ,80895 & \\
\hline \multirow{2}{*}{ Relação Socioprofissional } & Residente & 46 & 2,8609 & ,89628 & \multirow{2}{*}{,83 } \\
\hline & Preceptor & 30 & 2,8267 & ,76786 & \\
\hline \multirow{2}{*}{ Exaustão Emocional } & Residente & 46 & 2,7283 & ,66954 & \multirow{2}{*}{, 47} \\
\hline & Preceptor & 30 & 2,4806 & ,68218 & \\
\hline \multirow{2}{*}{ Desumanização } & Residente & 46 & 2,2630 &, 71192 & \multirow{2}{*}{,86 } \\
\hline & Preceptor & 30 & 2,1800 & ,69003 & \\
\hline \multirow{2}{*}{ Decepção no Trabalho } & Residente & 46 & 2,3930 & ,61969 & \multirow{2}{*}{,83 } \\
\hline & Preceptor & 30 & 2,2744 & ,66162 & \\
\hline
\end{tabular}




\begin{tabular}{|c|c|c|c|c|c|}
\hline Estado Civil & & & & & \\
\hline & Solteiro & 29 & 2,3310 & ,88403 & \\
\hline \multirow[t]{3}{*}{ Condições de Trabalho } & Casado ou União Estável & 42 & 2,7571 & 1,12708 & ,39 \\
\hline & Divorciado & 5 & 3,0000 & 1,17898 & \\
\hline & Solteiro & 29 & 3,5611 & ,59069 & \\
\hline \multirow[t]{3}{*}{ Organização do Trabalho } & Casado ou União Estável & 42 & 3,5346 & ,71305 &, 59 \\
\hline & Divorciado & 5 & 3,4909 & ,65113 & \\
\hline & Solteiro & 29 & 2,8897 & ,98429 & \\
\hline \multirow[t]{3}{*}{ Relação Socioprofissional } & Casado ou União Estável & 42 & 2,8810 & ,73160 & ,42 \\
\hline & Divorciado & 5 & 2,3200 & ,82280 & \\
\hline & Solteiro & 29 & 2,8305 & 69525 & \\
\hline \multirow[t]{3}{*}{ Exaustão Emocional } & Casado ou União Estável & 42 & 2,5337 & ,66107 & ,33 \\
\hline & Divorciado & 5 & 2,2833 &, 54199 & \\
\hline & Solteiro & 29 & 2,4207 & ,66942 & \\
\hline \multirow[t]{3}{*}{ Desumanização } & Casado ou União Estável & 42 & 2,1286 & ,69923 & ,25 \\
\hline & Divorciado & 5 & 1,9800 & ,76616 & \\
\hline & Solteiro & 29 & 2,5172 & 60983 & \\
\hline \multirow[t]{2}{*}{ Decepção no Trabalho } & Casado ou União Estável & 42 & 2,2399 & ,64003 & ,81 \\
\hline & Divorciado & 5 & 2,2462 & ,64220 & \\
\hline
\end{tabular}

Fonte: Vasconcelos NA, et al. 2019. 
Em seguida, foi executa a análise de Regressão Linear Múltipla para verificar a natureza da relação entre os construtos investigados. Nesses casos, quanto mais perto $1 /-1$ for o coeficiente, mais forte será sua capacidade de explicação (RAMOS MFH, et al. 2016).

A variável critério foi a Síndrome de Burnout, representada por exaustão emocional, desumanização e decepção no trabalho. A explicativa foi o Contexto de Trabalho, constituída pela organização do trabalho, relações socioprofissionais e condições de trabalho. $O \mathrm{R}^{2}$ ajustado é o nível de estimativa ou poder explicativo da regressão. $O \mathrm{R}^{2}$ elucide quanto da variação de uma variável dependente, neste caso, é o Burnout, recebe influência do contexto de trabalho (Tabela 4).

Os coeficientes de determinação $\left(R^{2}\right)$, obtidos na análise de regressão linear múltipla mostrou que $0,427 \%$ da variação da Burnout foi explicada pelo contexto de trabalho. O fator Relações Socioprofissionais foi quem mais detém relação com a síndrome $(\beta=0,419)$, e a exaustão emocional é dimensão que mais sofre impacto do contexto de trabalho $\left(R^{2}=0,427\right)$ (Tabela 4$)$.

Tabela 4 - Regressão linear múltipla do contexto de trabalho sobre a presença da Síndrome de Burnout entre residentes e preceptores de ortopedia e traumatologia, $n=76$. Recife-PE, 2019.

\begin{tabular}{|c|c|c|c|c|c|c|c|c|}
\hline & \multicolumn{2}{|c|}{$\begin{array}{l}\text { Exaustão } \\
\text { Emocional }\end{array}$} & \multicolumn{2}{|c|}{ Desumanização } & \multicolumn{2}{|c|}{$\begin{array}{l}\text { Decepção no } \\
\text { Trabalho }\end{array}$} & \multicolumn{2}{|c|}{ Burnout (Geral) } \\
\hline & B & $\beta$ & B & $\beta$ & B & $\beta$ & B & $\beta$ \\
\hline $\begin{array}{l}\text { Condições de } \\
\text { Trabalho }\end{array}$ & 0,015 & 0,023 & 0,126 & 0,190 & 0,123 & 0,205 & 0,087 & 0,146 \\
\hline $\begin{array}{l}\text { Organização do } \\
\text { Trabalho }\end{array}$ & 0,289 & 0,279 & 0,102 & 0,096 & 0,198 & 0,205 & 0,202 & 0,211 \\
\hline $\begin{array}{l}\text { Relações } \\
\text { Socioprofissionais }\end{array}$ & 0,349 & 0,432 & 0,346 & 0,417 & 0,252 & 0,334 & 0,312 & 0,419 \\
\hline & $R^{2}$ ajus & $\begin{array}{l}=0,427 \\
=0,403 \\
=0,653\end{array}$ & $\mathrm{R}^{2}$ ajuste & $\begin{array}{l}R^{2}=0,363 \\
\text { do }=0,336 \\
R=0,602\end{array}$ & $R^{2}$ ajus & $\begin{array}{l}R^{2}=0,378 \\
\text { do }=0,352 \\
R=0,615\end{array}$ & $\mathrm{R}$ & $\begin{array}{r}=0,433 \\
\text { stado }= \\
0,410 \\
=0,658\end{array}$ \\
\hline
\end{tabular}

Fonte: Vasconcelos NA, et al. 2019.

\section{DISCUSSÃO}

O objetivo deste estudo foi analisar o contexto de trabalho e Síndrome de Burnout em residentes e preceptores das residências médicas em ortopedia e traumatologia no estado pernambucano. No tocante ao contexto de trabalho, a organização do trabalho foi a mais acentuada. No entanto, a organização do trabalho possui estreita relação com os processos de saúde-doença do trabalhador. A definição organização do trabalho pode ser vista em duas esferas, uma diferenciada pela divisão do trabalho, no qual estão pautadas as tarefas, os processos prescritos, entre outros. Na outra esfera é a divisão dos homens, em que estão as relações de poder, autonomia no trabalho e as hierarquias, comunicação e cooperação, dentre outras (GIONGO CR, et al. 2015).

Além disso, a organização do trabalho exerce grandes influências na saúde psíquica dos trabalhadores da saúde, como também as condições de trabalho desfavoráveis, na falta de apoio organizacional, reverberado pela insegurança, impotência e fragilidade ao presenciar situações dolorosas (SALDANHA DA SILVEIRA CCS, et al. 2019).

Ferreira MC e Mendes AM (2008) corroboram a situação da organização de trabalho é preocupante, podendo reverberar sobre a saúde e bem-estar dos médicos, visto que tal quadro necessita de medidas 
interventivas a curto e médio prazo, os aspectos mais críticos referem-se a forte cobrança por resultados, as rígidas normas para execução das tarefas e a falta tempo para realizar pausas de descanso no trabalho. Situações semelhantes são deparadas em outas investigações que versam à falta de autonomia profissional (REIS DDO, et al., 2018). Afora, as exigências e cobranças podem contribuir com a burocratização da relação médico e paciente, comprometendo o diálogo autêntico e a comunicação interprofissional (PREVIATO GF, BALDISSERA VDA, 2018).

A população estudada apresentou índices baixo-moderados de Burnout, mas em estudos estrangeiras tal dado varia em $50 \%$ a $74 \%$, e no Brasil a ocorrência foi de $50 \%$ a $81,5 \%$. A dualidade de papeis exercida pelos preceptores e residentes, torna 0 trabalho na residência médica, incontestavelmente, suscetível ao surgimento do Esgotamento Psicológico (BOND MMK, et al. 2018).

A exaustão emocional foi à dimensão mais acentuada da síndrome, o que corrobora os achados de outras investigações (NEVES VF, et al. 2015). É importante frisar que a exaustão emocional indica a pressão vivenciada por residentes e preceptores no contexto onde desenvolvem suas atividades. Boa parte da literatura toma a exaustão emocional como principal componente do Burnout (TAMAYO MR, 2015).

Entretanto, é importante encarar o Esgotamento Psicológico como fenômeno multidimensional, pois, afora a exaustão, presente também no estrasse ocupacional, tal síndrome congrega aspectos atitudinais, como é o caso da dimensão desumanização, a qual é a menos explorada no modelo tridimensional de Maslach e colaboradores. Para alguns pesquisadores, a desumanização é o fator mais distinto da Síndrome de Burnout, já que empreende situações do estresse interpessoal, muitas vezes vivenciado entre cuidador e paciente (MEDEIROS-COSTA, et al. 2018).

Por sua vez, os aspectos sociodemográficos são considerados possíveis causadores da deterioração a saúde mental. A associação entre a variável sexo indicou que as mulheres apresentam maiores escores em todos os fatores. As mulheres percebem-se mais exaustas e sobre carregada. Tal evidência é analisada em outras pesquisas, as quais associam isso à dupla ou tripla jornada de vida que muitas delas são submetidas (CARLOTTO MS, 2011).

O contexto de trabalho é preditor da Síndrome de Burnout, sendo as relações socioprofissionais quem mantém maior impacto. Esses fenômenos não fazem parte de uma única equação lúcida, mas coexistem e se influenciam dialeticamente (BARBOSA KKS, et al. 2012). No estudo conduzido Carreiro BO, et al. (2015), o contexto de trabalho também manteve relações com o Burnout, principalmente, os fatores organização do trabalho e relações socioprofissionais.

Mas, a síndrome é bastante influenciada pelas condições de trabalho, pois em outra investigação, observou-se correlações significativas e elevadas entre os fatores do Esgotamento Psicológico e aspectos do contexto de trabalho (organização do trabalho, condição de trabalho e relações socioprofissionais). Constatou-se que a exaustão emocional é fortemente associada aos três fatores do contexto de trabalho, mas a organização do trabalho se destaca enquanto variável preditora nas análises de regressão, demonstrando a importância de analisar aspectos referentes ao planejamento e prescrições do trabalho (ANDRADE AL, et al. 2015).

Ao verificar a qualidade de vida da residência médica em ortopedia no cenário brasileiro, Araújo ALDSL et al. (2019), conferiram índices que variaram entre bom a muito bom, sendo que os autores elencaram possíveis intervenções, como os fortalecimento dos relacionamentos interpessoais, promover espaços de diálogo entre trabalhadores dos programas de residência e serviços de saúde, cuidados de saúde e sono, prevenção e controle dos riscos psicossociais no trabalho, como estratégias de enfretamento e promoção do bem-estar.

Medidas preventivas e ações interventivas devem ser introduzidas conforme a necessidade de cada profissional, ao levar em consideração que o combate ao Burnout não depende apenas intervenções prémoldadas, mas na adoção de recursos multifacetados. Geralmente, as propostas de intervenções para prevenção da síndrome classificam-se em estratégias individuais, organizacionais e combinadas (SILVA JF, et al. 2020). No estudo conduzido por Saldanha da Silveira CCS et al. (2019) revelou que a utilização apenas de estratégias individuais poderá não ser capaz de evitar sofrimento e adoecimento. Destaca-se que a garantia a saúde não é de responsabilidade tão-somente do trabalhador, mas também da organização. 
De acordo com Medeiros-Costa ME et al. (2018) investigações intervencionistas envolvendo a síndrome do esgotamento psicológico ainda são incipientes. As técnicas adotadas não necessariamente visam modificações nas condições de trabalho ou organização do trabalho propriamente dito (com intuito de evitar o aparecimento ou lidar com o Burnout). Tais pesquisas buscam, prioritariamente, conscientizar os trabalhadores acerca da existência da síndrome através de cursos (visando à difusão de informações) e treinamentos direcionados à redução e/ou enfrentamento do estresse, bem como o engajamento em grupos de apoio.

No entanto, é necessário apontar algumas limitações relacionadas a este estudo. Uma delas, refere-se ao número de participantes, inviabilizando generalizações. A realização de um estudo com a participação de outras residências médicas poderia possibilitar uma visão mais ampla a respeito do contexto de trabalho dos residentes preceptores. A veridicidade nas respostas dos participantes se qualifica como limitação, pois a aplicação de escalas quantitativas tende a subestimar o nível de Burnout experimentado. Sugere-se novos estudos que visem explorar e averiguar o processo de trabalho nas residências e a manifestação de outros riscos psicossociais. Investigações de natureza longitudinais, aprofundando-se em analisar a relação e impacto do contexto de trabalho na residência médica e a manifestação do Esgotamento Psicológico são necessárias.

\section{CONCLUSÃO}

O estudo permitiu verificar a relevância do impacto do contexto de trabalho na experimentação do Burnout entre preceptores e residentes. Explorar as dimensões do contexto de trabalho que podem impactar 0 surgimento do esgotamento é de suma importância para o planejamento de ações interventivas. $O$ contexto de trabalho da residência médica em ortopedia e traumatologia pernambucana apresentou níveis que indica "situação-limite", vulnerável ao mal-estar e risco de adoecimento. A Síndrome de Burnout apresentou níveis baixo-moderados para desumanização decepção no trabalho e exaustão emocional. As condições de trabalho dos residentes e preceptores mostrou diferenças e, destaca-se que o contexto de trabalho da residência médica corrobora o surgimento do Burnout. Sugerem-se, assim, novas investigações que explorem os fenômenos que circunscrevem o contexto de trabalho da residência médica e a manifestação de outros riscos psicossociais.

\section{REFERÊNCIAS}

1. ANDRADE AL, et al. Burnout, clima de segurança e condições de trabalho em profissionais hospitalares. Rev. psicol. organ. trab. 2015; 15(3): 233-245.

2. ARAÚJO ALDSL, et al. Avaliação da Qualidade de Vida dos Residentes de Ortopedia Brasileiros. Revista Brasileira de Educação Médica. 2019; 43(1): 219-227.

3. AUTONOMO FRDO, et al. A Preceptoria na formação médica e multiprofissional com ênfase na atenção primáriaAnálise das Publicações Brasileiras. Revista Brasileira de Educação Médica. 2015; 39(2): 316-327.

4. BARBOSA KKS, et al. Sintomas depressivos e ideação suicida em enfermeiros e médicos da assistência hospitalar. Rev Enferm UFSM. 2012; 2(3): 515-522.

5. BOND MMK, et al. Prevalência de Burnout entre Médicos Residentes de um Hospital Universitário. Revista Brasileira de Educação Médica. 2018; 42(3): 97-107.

6. CAVALCANTI IL, et al. Burnout e depressão em residentes de um Programa Multiprofissional em Oncologia: estudo longitudinal prospectivo. Rev. bras. educ. méd. 2018; 42(1):190-198.

7. CARLOTTO MS. Síndrome de Burnout em professores: prevalência e fatores associados. Psicol Teor Pesqui. 2011; 27(4): 403-410.

8. CARREIRO BO, et al. Prevalência da síndrome de burnout em médicos de uma instituição hospitalar federal de ensino. Revista de Pesquisa Cuidado é Fundamental Online, 2015; (7): 39-48

9. FERREIRA MC, MENDES AM. Trabalho e riscos de adoecimento: o caso dos auditores fiscais da Previdência Social brasileira. Brasília: Edições LPA/FENAFIS, 2003; 156.

10. FERREIRA MC, MENDES AM. Contexto de Trabalho. In: Siqueira MMM. Organizadora. Medidas do comportamento organizacional: ferramentas de diagnóstico e de gestão. Porto Alegre: Artmed, 2008; p. 111-123.

11. GIONGO $\mathrm{CR}$, et al. Psicodinâmica do trabalho no Brasil: revisão sistemática da literatura. Temas psicol. 2015; 23(4):803-814.

12. LACERDA RB, et al. Contexto de trabalho e Síndrome de Burnout na equipe de Enfermagem da Estratégia Saúde da Família. Cultura de los Cuidados, 2016; 20(44): 91-100. 
13. MASLACH C. Entendendo o Burnout. In: ROSSI AM, PERREWÉ PL, SAUTER SL. Organizadores. Stress e Qualidade de Vida no Trabalho: Perspectivas atuais da Saúde Ocupacional. São Paulo: Atlas, 2005; p. 41-55.

14. MEDEIROS MRB, et al. Saúde Mental de Ingressantes no Curso Médico: uma Abordagem segundo o Sexo. Rev. bras. educ. méd. 2018; 42(3): 214-221.

15. MEDEIROS-COSTA ME, et al. Transtornos Mentais Comuns e Síndrome de Burnout em Agentes Penitenciários. Ciencia \& trabajo, 2018; 20(61): 36-41.

16. MEDEIROS-COSTA ME, et al. The professional exhaust in nursing: an analysis of the scientific production of theses and dissertations. Journal of Nursing UFPE on line, 2017; 11(4): 1731-1744.

17. NEVES VF, et al. Síndrome de burnout: impacto da satisfação no trabalho e da percepção de suporte organizacional. Psico (Porto Alegre). 2014; 45(1): 45-54.

18. PASTURA PSVC, et al. Burnout à Estratégia de Grupo na Perspectiva Balint: Experiência com Residentes de Pediatria de um Hospital Terciário. Rev Bras Educ Med. 2019; 43(2): 32-39.

19. PORTZ RM, AMAZARRAY MR. Transtornos mentais comuns e fatores associados em trabalhadores bancários do Rio Grande do Sul, Brasil. Rev. psicol. organ. trab. 2019; 19(1): 515-522.

20. PREVIATO GF, BALDISSERA VDA. A comunicação na perspectiva dialógica da prática interprofissional colaborativa em saúde na Atenção Primária à Saúde. Interface - Comunicação, Saúde, Educação, 2018; 22(Supl. 2): $1535-1547$.

21. RAMOS MFH, et al. Job satisfaction in teaching: An analysis based on the social cognitive model of job satisfaction and collective teaching effectiveness. Estud psicol (Natal), 2016; 21(2): 179-91.

22. REIS DDO, et al. Nem herói, nem vilão: elementos da prática médica na atenção básica em saúde. Ciência \& Saúde Coletiva, 2018; 23(8): 2651-2660.

23. SALDANHA DA SILVEIDA CC, et al. Sofrimento de trabalhadores da atenção básica em um contexto de tragédia: estratégias para evitar o adoecimento. Revista Eletrônica Acervo Saúde, 2019; 11(15): e1296.

24. SANT'ANA ERRD, PEREIRA ERS. Preceptoria médica em serviço de emergência e urgência hospitalar na perspectiva de médicos. Revista Brasileira de Educação Médica, 2016; 40(2): 204-215.

25. SILVA JF, et al. Síndrome de Burnout em profissionais de Enfermagem no contexto da Atenção Básica. Revista Eletrônica Acervo Saúde, 2020; (39): e2320.

26. STREINER D. Starting at the beginning: an introduction to coefficient alpha and internal consistency. J Pers Assess. 2003; 80(1): 99-103.

27. TAMAYO MR, TRÓCCOLI BT. Construção e validação fatorial da Escala de Caracterização do Burnout (ECB). Estud psicol (Natal), 2009;14(3): 213-21.

28. TAMAYO MR. Burnout. In: BENDASSOLLI PF, BORGES-ANDRADE JE, Organizadores. Dicionário de Psicologia do Trabalho e das Organizações. São Paulo: Casa do Psicólogo; 2015. p. 139-46. 